\title{
Geoffrey Chaucer y el MECENAZgo FEMENINO EN LA CORTE INGLESA BAJOMEDIEVAL
}

\author{
Ma Beatriz Hernández Pérez
}

Resumen: Este artículo plantea la existencia de redes de patronazgo literario entre las damas de la corte angevina en la segunda mitad del siglo XIV inglés. La producción literaria concerniente a la temática amorosa, y en particular "La leyenda de las buenas mujeres" de Geoffrey Chaucer, muestran que en la corte inglesa existió un clima de debate en torno a la imagen que de las mujeres se debía transmitir. Según demuestra el cotejo de los textos y la propia voz del poeta, las damas de su entorno más cercano serían esenciales para entender algunos de los temas y aproximaciones chaucerianas a sus personajes femeninos. Asimismo, se tratan las relaciones hispanobritánicas en estos momentos y la vinculación de Chaucer con la "empresa castellana" de Juan de Gante y Constanza de Castilla.

Palabras clave: patronazgo femenino, Chaucer, "La leyenda de las buenas mujeres".

Enviado a dictamen: 06 de agosto de 2008.

Aprobación: 05 de noviembre de 2008.

Dra. Mª Beatriz Hernández Pérez, doctora en Filología por la Universidad de La Laguna, Universidad de La Laguna, dirección: departamento de Filología Inglesa y Alemana, Facultad de Filología, Universidad de La Laguna, Campus de Guajara s/n, 38071, Tenerife, Islas Canarias, España; temas de investigación: literatura medieval inglesa, estudio de las mentalidades, estudios de género, hagiografía, correo electrónico: bhernanp@ull.es.
Abstract: This article proposes the existence offemale patronagenets among the Angevine courtly dames in the second half of fourteenthcentury England. Chaucer's love poems, especially "The Legend of Good Women", reveal a climate of debate regarding the proper image of women to be presented by poetry. Resorting to textual analysis and to the poet's own commentaries, the article defends the relevance of those ladies close to the poet in order to understand some Chaucerian topics and approaches to his female characters. The work also deals with British-Hispanic relationships in the late Middle Ages and with Chaucer's link to John of Gaunt's and Constanza of Castile's "Castilian enterprise".

Key words: female patronage, Chaucer, "The Legend of Good Women".

\section{Introducción: Mujeres, literalidad y cortesía}

$\amalg$ patronazgo femenino sobre las artes que se ejerció a lo largo de los siglos medievales ha constituido uno de los campos más fértiles dentro del estudio de las mujeres en el Medievo, ${ }^{1}$ al revelar que el mecenazgo de las diversas expresiones artísticas se dio en prácticamente todos los países. De entre las 
figuras más relevantes de los reinos occidentales, la de Leonor de Aquitania ha sido quizás la más destacada, al sintetizar algunos de los logros femeninos de la cultura y la sociedad de entonces, como el despliegue del amor cortés, o la participación femenina en la política nacional e internacional del momento (que, en su caso, incluyó la iniciativa de la cruzada, o la de la formación del imperio angevino). Sin embargo, quizás el rasgo más llamativo de esta reina haya sido su capacidad para aglutinar a su alrededor las más diversas manifestaciones de la vida artística del momento, y de proyectar esta red hacia los territorios en los que las mujeres de su familia pronto harían sentir las mismas sensibilidades. Es precisamente este aspecto del tejido cultural — particularmente el literario- como manifestación de la relevancia que alcanzaron algunas mujeres lo que intentará discernir este trabajo. Si bien las relaciones entre Inglaterra y Francia son relativamente bien conocidas en este sentido, las hispano-británicas no han sido tan profundamente estudiadas: Geoffrey Chaucer, poeta señero de la segunda mitad del siglo XIV inglés, será el personaje sobre el que fijemos nuestra atención, ya que parte de su producción posiblemente respondió a peticiones femeninas. El análisis del contexto literario en que se desarrolló este momento de su carrera, así como el de algunos de sus textos en relación con la política hispano-británica, pueden ayudarnos a comprender la manera en que las damas de la corte angevina no sólo intentaron llevar a cabo arriesgadas empresas políticas, sino encauzar la producción cultural del momento. La interpretación del legado chauceriano en esta clave nos puede alertar sobre la formación de una conciencia de grupo entre ellas, que hoy podríamos denominar de género. Desde dicha conciencia las mujeres de la corte inglesa se encontrarían capacitadas para debatir con autoridad la naturaleza de hombres y mujeres, y para seleccionar y en cierta manera dirigir los derroteros literarios del entorno áulico.

La práctica del mecenazgo femenino se ha venido a justificar como casi naturalmente vinculada a lo femeni- no, dada las particularidades que los padres de la Iglesia asignaron a la naturaleza femenina. ${ }^{2}$ Dentro del programa exegético del cristianismo temprano, se vincula la aparición de la mujer como signo externo a la pérdida de la pureza lingüística. El lenguaje divino, uno en sí mismo e infalible, se ve quebrado en este modelo por la aparición de un sistema genérico binario en el que la mujer recibe un rango ontológico inferior al del hombre. En dicho modelo lingüístico, se considera a su vez femenina la parte meramente "carnal" del lenguaje, la faceta identificable con la literalidad casi física y limitada de todo mensaje, mientras que el subterfugio simbólico, donde se aloja el significado último, complejo y verdadero, se viene a identificar con el espíritu, vinculado al principio masculino (Bloch, 1991: 37-63; Potkay y Evitt, 1997). Paradójicamente, la entrada en el mundo de ese principio femenino, sobrante, innecesario, ornamental y en última instancia engañoso hacía que todo lenguaje resultara de entrada deficiente, que estuviera desequilibrado en sus bases, dada la desigualdad de sus fundamentos, y por tanto, que llevara a una eterna confusión. Era esa falta de entendimiento la responsable de que la humanidad se hubiera visto privada del paraíso primigenio, y venía a justificar la necesidad del comentario exegético que explicara el significado profundo de todo texto, más allá del superficial reclamo retórico. Así pues, la explicación de todo signo quedaba irremediablemente atada a la capacidad decorativa, meramente superficial y "femenina" del lenguaje. Se consideraba femenino el adorno prescindible, lo no esencial, aquello que servía para captar la atención; así, para alcanzar la verdad profunda de todo mensaje, el signo material — marcado por la percepción sensorial (principalmente visual o auditiva) — tenía que ser superado, trascendido. La propia mujer, origen de la confusión y víctima y agente del engaño, era por tanto entendida como un signo a descifrar y desmontar, labor a la que se entregará toda una caterva de autores.

Casi por afinidad, pues, se les asignaron a ellas ámbitos de gestión como el del cuidado del cuerpo y 
los aspectos decorativos en su conjunto, y en ocasiones el patrocinio de las artes. Dentro de su dominio caía igualmente el dictamen sobre las maneras: la cultura cortesana que empieza a fraguarse a fines de la Alta Edad Media confía a lo femenino la atención a las formas que han de caracterizar las aptitudes cortesanas. La feminización del entorno aristocrático se vincula a su vez con el surgimiento de un código de expresión — de exteriorización — de la subjetividad masculina que empieza a valorarse, tal y como queda articulado en la literatura de los romances y en la lírica amorosa. En dichos "modelos de conducta" literarios, las mujeres vuelven a quedar bosquejadas como agentes que sacan a la superficie, que provocan, de hecho, los impulsos vitales masculinos, favoreciendo el manifiesto desarrollo físico y espiritual del héroe mediante el lenguaje y la conducta corteses. Esta literatura destinada a saciar las ansias narcisistas del estamento noble moldea y vuelve visible una figura femenina, la de la dama, a la que dota de ciertos "privilegios". La altivez que demuestran las mujeres en estas piezas literarias proviene posiblemente de una sublimación estética hasta entonces no experimentada y por la que se escoge a la dama como objeto estético por excelencia: la belleza femenina, hasta entonces apenas comentada, comienza a remitir a una sensibilidad estética que la cultura cortesana se atribuye.

\section{Política internacional y literatura cortesana: el entorno de Geoffrey Chaucer}

En la segunda mitad del siglo XIV la corte inglesa de Eduardo III estaba todavía plenamente imbuida de ese sentir cortés que hacía de las damas y los caballeros auténticos modelos de conducta, es decir, agentes de exteriorización de un majestuoso temperamento grupal según el cual las atribuciones genéricas parecían bien delimitadas. En esta corte, como en otras anteriores, las mujeres, conscientes de sus capacidades en los diversos campos de acción que les eran confiados, aparecen vinculadas directamente al mecenazgo literario. Hasta qué punto estas gestiones pueden haber alimentado una conciencia de grupo entre ellas, hasta dónde llegó la influencia de dichas pautas — a través de la literatura y las artes por ellas inspiradas - en la vida del resto de los grupos sociales, de qué forma sintieron y creyeron en su poder, y en qué medida esta capacidad de gestión fue sistemáticamente contestada por el orden patriarcal son cuestiones que van más allá de este trabajo. Sin embargo, se puede intentar atender a algunos de estos aspectos, como el de la existencia de ciertos hábitos - sobre todo el de la lectura conjunta o el mecenazgo a poetas - por los que las mujeres orientarían hacia sus intereses particulares o genéricos la producción literaria.

Resulta ilustrativo el caso de Geoffrey Chaucer, considerado como "padre de la literatura inglesa", dado el impulso que su aportación supuso para el prestigio cultural del inglés como lengua nacional y literaria, sustituyendo en ese sentido al francés. Hasta entonces, la lengua y los géneros literarios franceses eran los que habían contenido la cultura cortés en Inglaterra, y así, a principios de la segunda mitad del siglo XIV, la corte inglesa contaba con la presencia de figuras tan señeras como la del rey Juan II de Francia, que a partir de su derrota en Poitiers, estuvo cautivo entre los cortesanos ingleses hasta 1360, y fue reemplazado tras el tratado de Brétigny por sus hijos Louis, Jean y Philippe - los futuros duques de Anjou, Berry y Borgoña - como rehenes de lujo. ${ }^{3}$ Al coincidir precisamente con treguas como la de 1360-1369, la corte inglesa rebosaba de poetas y eruditos (Calin, 1984; Wimsatt, 1993) ${ }^{4}$ para los que el francés constituía una señal de distinción y exquisitez literaria. Sin embargo, la herencia normanda de los reyes ingleses auguraba el nacimiento de un sentimiento imperialista entre la dinastía Plantagenet — sobre todo a partir de Enrique II-que llevó paulatinamente a un progresivo desapego por la lengua francesa, identificada con el rival en dichos afanes imperialistas. En el siglo XIV, el sentimiento nacionalista, intensificado por la Guerra de los Cien Años, había contribuido al desarrollo del inglés 
como lengua hablada entre la nobleza; sin embargo, tanto la literatura escrita como muchos de los documentos oficiales seguían vertiéndose en francés o en latín. ${ }^{5}$ Podríamos cuestionarnos si la decisión chauceriana de escribir en inglés responde en parte a una necesidad de contentar a las damas de la corte, que por lo general leían el inglés y el francés (Meale, 1993: 128-158; Penketh, 1997: 266-280). Para contestar, creo esencial señalar que uno de sus primeros trabajos fue precisamente el de la traducción al inglés de alrededor de un tercio de una de las obras claves de la literatura francesa, Le roman de la rose. Aunque ignoramos las circunstancias que le llevaron a este ejercicio, lo cierto es que delata una conciencia clara de la necesidad de divulgar en su lengua materna los secretos del libro. Esta traducción y la redacción de "El libro de la duquesa" le granjearían la fama suficiente para presentarse como compositor en una corte que, como veremos, no era su ambiente natural, por lo que siempre se movió en ella con cautela.

Efectivamente, nacido a principios de los años cuarenta, Geoffrey Chaucer no proviene de la nobleza sino del patriciado urbano. Posiblemente fue su padre, proveedor de vino de la casa real, quien logró que se le incluyera entre el servicio de uno de los hijos de Eduardo III (1312-77), el futuro duque de Clarence, Lionel de Antwerp (1338-68) y de su esposa, Elisabeth de Úlster (1332-63), siendo en la corte donde el joven aprendería el francés (Butterfield, 1997: 82-120; Rigg, 1997: 121-141). Como escudero de Lionel lo vemos en su temprana juventud luchando en Francia ${ }^{6}$, aunque cuando Lionel y Elisabeth partan hacia Irlanda en 1361 él se queda en Inglaterra, quizás porque ya hubiera empezado a cortejar por entonces a la que acabó siendo su esposa, Philippa —-dama de compañía de la reina Felipa de Hinault-, con la que se casa en 1366 (Braddy, 1949: 342-343; Galway, 1960: 481487). Parece que ambos cónyuges entrarían a formar parte del séquito real, pues Chaucer aparece nombrado en esos años como valettus, escudero real.

Desde su condición de sirviente se le empieza a disponer en una serie de servicios que él alternaría con la composición de poemas como "El libro de la duquesa" o la traducción de Le roman de la rose; en estos servicios se mueve desde la posible participación en el campo de batalla hasta la probable labor de intérprete en misiones diplomáticas importantes, de las que las más sonadas son las que lo llevaron a Francia y a Italia. Pero entre sus viajes menores destaca en 1366 uno a Navarra — junto con otros tres acompañantes anónimos-del que sólo se sabe que la cancillería real navarra de Carlos II el Malo emitió el salvoconducto que le permitió viajar a través del reino entre finales de febrero y mayo. ${ }^{7}$ El misterioso viaje supone el cimiento de la relación entre Chaucer y España, y lo sitúa en medio de la ajetreada política internacional inglesa dispuesta junto al rey Pedro I de Castilla contra su hermano Enrique de Trastámara. Según la hipótesis de Serrano Reyes (1996:117-145), Chaucer habría venido a persuadir a los caballeros ingleses — entre los que destacaría Sir Hugh Calveley- que habían tomado el bando de Du Guesclin y Enrique de que abandonaran dicho apoyo, y a recordarles el tratado firmado en 1362, por el que los caballeros ingleses tenían prohibido luchar del lado trastámara. Baugh (1968: 66) destaca que ante las repetidas peticiones de auxilio por parte de Pedro I, Eduardo III de Inglaterra había enviado una carta a Calveley y a otros caballeros el 6 de diciembre de 1365 , pero que al no llegar a tiempo, se decidiría por enviar también la comitiva de Chaucer a dar la orden directamente. ${ }^{8}$

Tras viajar de nuevo en 1368 a Milán ${ }^{9}$ el poeta vuelve a Francia en 1369, año en que mueren tanto la popular reina Felipa como la condesa Blanca de Lancaster, primera mujer del príncipe Juan de Gante; muertes que preludian el declive de una vida cortesana insuperable, en la que la figura relevante —mientras el primogénito Príncipe Negro residía en Aquitania y el príncipe Lionel en Irlanda- había llegado a ser este Juan de Gante, protector de Chaucer desde entonces. ${ }^{10}$ Será dicho hijo de Eduardo III quien rija los destinos ingleses durante la minoría de edad del futuro Ricardo II, quien cuenta sólo diez años cuando hereda el trono inglés (su padre, 
Eduardo el Príncipe Negro, muere en 1366 y su abuelo Eduardo III en 1367).

Tras haber servido en diversas embajadas y escaramuzas guerreras, en 1374 la casa real recompensa al poeta concediéndole el puesto de inspector de aduanas en el puerto de Londres, y allí, en la vivienda de la puerta de Aldgate que vigila la muralla de la ciudad, se dedica a componer "La casa de la Fama". Considerado y aún remunerado puntualmente como escudero de la casa real y al servicio de Juan de Gante, seguirá sirviendo de acompañante en embajadas ocasionales (entre 1377 y 1381 a Francia, y en 1378 a Italia)." Durante los últimos años de Aldgate, Chaucer pudo escribir también "El parlamento de las aves", "Troilo y Criseida" y el "Cuento del Caballero". Pero quizás debido a la marcha de su señor a España, o a que prefiriera internarse más a fondo en la literatura, a mediados de los ochenta abandona Londres, aprovechando que se le eleva al rango de juez de paz y de caballero por el condado de Kent. Un Chaucer probablemente viudo desde 1387 y que había solicitado la suspensión de su asignación anual —ante la amenaza que latía en Londres contra los beneficiados de antiguos dispendios de la corona - se las arregla para entablar relaciones con el hijo de Juan de Gante, Enrique de Bolingbroke (conde de Derby y futuro Enrique IV). Sería probablemente entre aquel refugio de Kent en los últimos años cuando escribiría "La leyenda de las buenas mujeres", así como la traducción perdida de De miseria humanae condicionis, Un tratado del astrolabio y otros poemas, y sobre todo Loscuentos de Canterbury. Entre 1389 y 1391 se le asigna el puesto Secretario de las Obras Reales, y más adelante el de guardabosque oficial de North Petherton (Somerset), regresando ocasionalmente a Kent para intentar acabar Los cuentos de Canterbury. En estas labores se encuentra cuando Juan de Gante retorna de su aventura española. Tanto él como el rey enviudarán pronto: Lancaster arreglará entonces su rápido matrimonio con Katherine Swynford, mientras que Ricardo coronará la reciente tregua con el país vecino con un segundo matrimonio (con Isabella de Francia).
Las constantes e intensas tensiones políticas entre tío y sobrino tendrán un estallido póstumo cuando, muerto Juan de Gante, Ricardo II torpemente fuerce la revuelta del hijo de aquél, sin lograr otra cosa que acelerar su propio derrocamiento y muerte y el nombramiento de su primo Enrique de Lancaster como Enrique IV. Hábil testigo de las escaramuzas políticas de ambas partes, Chaucer fija su residencia en Londres en diciembre de 1399, una vez se ha restaurado el orden político, y consigue del nuevo rey una pensión que mantendrá hasta su muerte al año siguiente.

\section{Entre las Chaucer y las Lancaster}

La figura del poeta ha estado comúnmente enlazada a la de Juan de Gante, su principal valedor. Resulta ciertamente difícil desvincularlos, si bien el nudo se vuelve mucho más visible cuando constatamos la relación de Chaucer con el entorno femenino de Lancaster. El desarrollo literario de este momento estuvo en gran manera auspiciado por las circunstancias generadas por las damas de la corte y sus posibles peticiones a los poetas, o por la huella que ellas habían dejado. En el caso de Chaucer, el ejemplo más evidente es el de la composición de su "Libro de la duquesa", una elegía encargada por Juan de Gante para cantar su dolor ante la pérdida de su primera esposa, Blanca de Lancaster. Si bien es el propio duque el que aparece como el personaje enlutado que lamenta la pérdida de su reina en una alegórica partida de ajedrez contra Fortuna, el caso es que la propia Blanca ya era famosa como mecenas literaria. Froissart la había alabado por su generosidad en su Le joli buisson de jonece y le había dedicado algunos de sus poemas; $y$ no es de extrañar esta generosidad ni su vinculación a la cultura, pues Blanca era una de las herederas más ricas del reino (Jambeck, 1996: 228-265; Webster, 1990; Anderson, 1947: 152-159), hija del duque de Lancaster, Henry Grosmont, autor de un tratado devocional, Lelivre des seyntz medicines, y de otro sobre las leyes de la guerra hoy perdido. No nos sorprende, por 
tanto, que en la temprana edición de la obra de Chaucer realizada por Speght, aparezca ya la duquesa Blanca como la patrona que solicitara su poema "ABC", en el que se suceden una serie de estrofas dirigidas a la Virgen por orden alfabético, posiblemente para ser usadas no sólo en la devoción privada de la dama, sino como método de aprendizaje de las más pequeñas de la corte; de hecho, de la mayor de las hijas de la duquesa, la que sería luego Philippa de Portugal. Adivinamos, pues, en este encargo un vínculo común entre las mujeres de la corte, el de la lectura común de poemas, que podían asimismo compartirse con las hijas, siguiendo el modelo sacro de la sesión de lectura entre Santa Ana y la Virgen María, ambas vinculadas con el aprendizaje de la palabra divina como preparación para la futura aceptación en el cuerpo de María de Jesús como el "verbo hecho carne". Este modelo de Santa Ana y la Virgen se convirtió en uno de los pocos en los que se mostraba el amor filial de las madres bajomedievales por sus hijas (Sheingorn, 2003: 105-134; Cullum y Goldberg, 2000: 217-236).

Otra figura femenina relacionada tanto con la duquesa Blanca como con Chaucer será una de las damas de compañía de aquélla, Katherine Swynford, quien tras la muerte de la duquesa se encargaría del cuidado de los huérfanos, y que en los años venideros se acabaría transformando en amante del viudo, quien exhibió dicha relación con impunidad, incluso tras celebrar segundas nupcias con Constanza, hija de Pedro I de Castilla. De hecho, Kathenine Swynford pasaría de ser ama de cría a madrastra de esta prole, pues terminaría siendo la tercera esposa de Juan de Gante tras la muerte de Constanza en 1394. Su relación con Chaucer no pudo ser más cercana: era nada menos que su cuñada, pues la hermana de Katherine no era otra que Philippa, la esposa del poeta, posiblemente la "Philippa Pan" que aparece en uno de los documentos como hija de Payne de Roet de Hinault, rey de armas de Guienne. Presumimos que este caballero habría colocado a sus dos hijas en la corte, vinculándolas al séquito de las esposas de Juan de Gante: Katherine estuvo desde el principio al servicio de Blanca; Philippa lo estuvo primeramente de la reina, pero al morir ésta - justamente un mes antes que Blanca de Lancaster, en 1369- y tras una breve estancia al servicio del duque, entraría en el séquito de Constanza de Castilla (que llegó a Inglaterra en 1372), pasando a ser una leal servidora de la española, como muestran los documentos en los que la hija de Pedro I se refiere a ella como "nôtre très chère compaigne" (Crow y Olson, 1966: 90). Su lugar de residencia estaría en Tutbury, en Staffordshire, donde Juan de Gante tenía el magnífico castillo de Kenilworth, y a donde posiblemente se dirigiría Chaucer en sus años de estancia en Aldgate para visitarla a ella y al primero de sus hijos. El poeta sabría de primera mano, pues, tanto de los amoríos de su cuñada Katherine con Juan de Gante como de su eco en los oídos de la princesa castellana.

En cuanto a la relación del duque de Lancaster con Constanza, se trató de un pacto político fraguado durante la guerra civil. Según Ybarra (1999), una vez Pedro I de Castilla supo de la entrada de su hermano Enrique en Burgos y Toledo, se dirigió a pedir ayuda directamente al Príncipe Negro, que se encontraba en Gascuña, a donde se dirigió con sus hijas (Beatriz, Constanza e Isabel). Juan de Gante participó tanto como testigo de los acuerdos de Libourne (1362), firmados entre los reyes castellano, navarro e inglés, como en la batalla de Nájera, en la que se situaría en la vanguardia de arqueros ingleses, mientras las hijas de Pedro y sus damas permanecerían en Burdeos como garantía del cumplimiento de las promesas castellanas. Tras la derrota de Montiel y la muerte de Pedro (1369), se formaría una pequeña corte alrededor de estas mujeres en Burdeos; Beatriz pronto se retiraría al monasterio de Tordesillas, renunciando a sus derechos, que pasarían a la joven Constanza. En estos años, dada la enfermedad que empezó a rondar al Príncipe Negro, fue su hermano Juan de Gante quien tomó el cargo de lugarteniente de Aquitania, y dado que tanto la familia real inglesa como estas infantas compartían la abadía de Santa Andrea, es comprensible que el duque, entonces viudo, aceptara el ofrecimiento 
de la corona castellana a cambio de una alianza con la causa petrista que se sellaría con el matrimonio de Juan de Gante y la infanta Constanza. La unión se celebró en 1371, y para garantizar la sucesión se añadió a ésta la boda entre la infanta Isabel y Edmundo, el hijo menor de Eduardo III. Así, desde 1372 Constanza y Juan de Gante se intitulan "reyes de Castilla y León". La cohorte de petristas que siguió a la castellana a Inglaterra influyó en que los intereses de la dama se centraran exclusivamente en recuperar el trono perdido, por lo que el asunto de los amoríos del Lancaster con Katherine Swynford no pareció alterarla en ningún momento, ${ }^{12}$ tanto es así que Constanza acepta que el nombre de su única hija sea nada menos que el de Catalina, demostrando así su tolerancia para con la amante ducal. No podemos adivinar si la intercesión de Philippa Chaucer tuvo que ver con el conformismo que parece haber caracterizado a Constanza o si pesaría incluso más el hecho de que su propia madre había sufrido una suerte parecida a la de Katherine. Así, ajena a todo lo que no fuera la recuperación de su reino, durante años la castellana vivió en sus residencias inglesas, rodeada de los fieles petristas y sumida en la discreción, mientras que la corte inglesa sí que se hizo eco de los amoríos de Juan y Katherine, dado que a lo largo de la empresa castellana de Constanza y Lancaster, conocida como "chemin de l'Espagne", llega un momento - tras el fracaso de la expedición de principios de los ochenta y la victoria de Aljubarrota - en que Lancaster, tras recibir el apoyo del Parlamento, de la Iglesia de Inglaterra y de los banqueros italianos, ha de representar en la corte una solemne petición de perdón público a su esposa, necesaria desde el punto de vista político; tras dicha escenificación, con el beneplácito y los obsequios reales, Juan de Gante, Constanza y su hija Catalina — seguidas por las demás hijas de Lancaster, Philippa e Isabel, y otra hija natural, Blanca — zarparon hacia Portugal en 1386 para emprender la reconquista del reino de Castilla. Para Jesús Serrano (1998: 193-203), resulta más que probable que entre las damas de com- pañía de estas señoras se encontrara la propia Philippa Chaucer, que, de hecho, podría haber muerto por el camino, o ya en la propia Lisboa, a causa de la peste que comenzó a asolar los ejércitos ingleses desde que arribaron a Galicia.

Tras celebrarse en febrero de 1387 el matrimonio entre Philippa de Lancaster y Joao I de Portugal, comenzaron en Troncoso las negociaciones secretas derivadas de la empresa reconquistadora: Constanza y Juan de Gante prefirieron conseguir la paz mediante los esponsales de su hija Catalina con el heredero de Juan I de Castilla, Enrique, que insistir en la lucha. Mientras Catalina permaneció en Castilla hasta que se celebró su boda en 1393, sus padres regresaron a Inglaterra, donde Constanza moriría un año después, alejada de las intrigas políticas de la corte ricardiana y dedicada al disfrute de la música y los divertimentos palaciegos en un particular retiro, ${ }^{14}$ cuando ya su marido había regresado a su amante Swynford y a sus largas temporadas en Gascuña. También en 1394 muere la amada reina de Ricardo II, Ana de Bohemia.

\section{Literatura cortesana para mujeres: amor y poder}

Aunque no tenemos pruebas de que Constanza de Castilla pidiera a Chaucer que compusiera para ella ninguna de sus obras, sí que podemos aventurar que la visión de la tragedia de Pedro I en el "Cuento del Monje" (dentro de Los cuentos de Canterbury), coincidiría con la que Constanza habría hecho llegar a Philippa, su mujer. Cierto que también pudo recibir esta información de testigos del suceso, como don Fernando de Castro, que había pasado al servicio de Juan de Gante ${ }^{15}$ y le contaría de primera mano el episodio del fratricidio. Chaucer no necesitaba de la versión de la huérfana para escribir su breve relato, pero con toda probabilidad la inserción de este episodio en la colección de tragedias que cuenta este monje narrador se debe a la influencia de Constanza de Castilla. He aquí el fragmento en cuestión (1987: 463): 
Noble y honorable Pedro, gloria de España, a quien la Fortuna elevó en tan gran esplendor, tenemos todos los motivos de lamentar tu muerte desgraciada. Tu hermano te arrojó de tu propia patria; más tarde, durante un asedio, fuiste engañado mediante una estratagema y conducido a una tienda en donde él mismo te mató con su mano, con lo que te sucedió en tu reino y prebendas. ¿Quién ideó esta villanía y este infame pecado? Un águila negra sobre campo de nieve, cogida en una rama pintada en rojo como una brasa ardiendo. ¿Quién ayudó al asesino en lo que necesitaba? Un nido de maldad. No un Oliver de Carlomagno, siempre escrupuloso en lealtad y honor, sino un Oliver-Ganelón, corrompido por sobornos, fue el que llevó al noble rey a la trampa.

Se trata de dos estrofas que narran la salida de Pedro de sus tierras y el episodio de Montiel, y en la segunda de las que - mediante la alusión heráldica- el narrador presenta como traidores franceses a Du Guesclin y a su sobrino Oliver de Mauny (ya conocidos desde antes de la muerte de Pedro como traidores, pues cuando Carlos II el Malo de Navarra dejó pasar por sus territorios a los franceses en 1367, lo hizo con su ayuda). Tras la muerte de Du Guesclin en 1380, el propio Deschamps había escrito una balada en la que describía sus motivos emblemáticos, destacando los mismos elementos que ahora introduce Chaucer: el campo plateado sobre el que destaca un águila bicéfala sobre bastón rojo. Aquí Chaucer se refiere a la rama pintada de rojo para cazar al ave, y de ahí deriva el motivo de la trampa en la que el propio Du Guesclin hará caer a Pedro. El nido de maldad al que se refiere nos devuelve a la imagen del águila, y a su vez, de la tienda como nido-trampa de esta feroz ave. El énfasis en el nombre de Oliver puede además implicar una referencia a Charles Olyver, un famoso caballero que había participado en Nájera, contrapuesto a este otro Oliver de Mauny. ${ }^{16}$ En cuanto a la datación del fragmento, se habla de dos momentos: en el primero, según aparece en algunos manuscritos, posiblemente se incluyó el adjetivo "tu bastardo hermano" aplicado al futuro rey Trastámara; sin embargo, en una segunda versión, fechada en un momento que auguraba la reunificación de emperejilados y trastámaras (gracias a los esponsales en 1388 de Catalina y el futuro Enrique III de Castilla), Chaucer se mostraría más cauto y extraería la referencia a la bastardía de Enrique II. Así pues, esta segunda versión es posible datar entre 1386 y $87,{ }^{17}$ justo cuando estaban en marcha las negociaciones de los esponsales. En el poema, aunque acusado de usurpador, asesino y ladrón (pues Chaucer dice "in thy regne" y "in thy rente"), no persiste el adjetivo "bastardo". De igual manera, parece quitar responsabilidades a Enrique al poner en mente de los franceses - y no en la del futuro monarca castellano_- la idea del asesinato de Pedro.

Además de esta clara referencia a Castilla en Los cuentos de Canterbury, existe en la obra chauceriana otro poema clave para la comprensión de las presiones femeninas sobre el poeta: se trata de "La leyenda de las buenas mujeres", una recopilación de diversos relatos clásicos de mujeres abandonadas por héroes legendarios inspirada en las Heroidas de Ovidio. Escrito alrededor de 1386 — coincide con la campaña española de Lancasteren estas nueve historias el vínculo que une a las mujeres protagonistas es el que se las representa como amantes nobles y leales. Del poema existen dos prólogos, en el primero de los cuales (F, Fairfax 16) destaca la mención a "la reina"; posiblemente dicha referencia sea a la primera esposa de Ricardo II, la bienamada Ana de Bohemia, a la que ya no se nombra en la segunda versión del prólogo, posterior a su muerte en 1394. Los versos del poeta dicen: "cuando tengas el libro escrito, entrégaselo a la reina de mi parte, en la residencia de Eltham o en la de Sheene" (F 496-97), por lo que se ha deducido que la obra fue solicitada por Ana; esta posibilidad se ve afianzada por las palabras de uno de los seguidores de Chaucer en el siglo XV, John Lydgate, quien en su Declive de los príncipes, da cuenta de la petición real a su maestro: "Este poeta escribió, a petición de la reina,/una leyenda, de perfecta santidad,/ de las buenas mujeres, de las que encontró 
nueve/que sobresalían en bondad y bellezas". Podemos asumir que Lydgate seguía lo que era la opinión común sobre Chaucer en su relación con la reina, aunque su afirmación puede proceder también de una simple lectura de los versos del prólogo. Aunque la reina debe contarse entre las posibles patrocinadoras del poema (si bien Ana apenas hablaba inglés), también pudo ser encargado por cualquier otra dama.

En el prólogo el poeta se refiere al debate cortesano que existía entre los seguidores de la hoja o de la flor, rivalidad derivada de los divertimentos en torno a la celebración del día de san Valentín en los que se formaban dos bandos cortesanos. ${ }^{18}$ Se sabe que Philippa — hija de Juan de Gante y Blanca de Lancaster- era seguidora de la flor, como de hecho lo fue la reina Ana de Bohemia, aquí posiblemente encarnada en la propia protagonista Alceste, a la que se presenta con los colores y valores de una flor, la margarita. ¿No sería factible que en momentos en que se preparaba la expedición a Castilla y se buscaba el beneplácito real para esta empresa, alguien del entorno de Lancaster pudiera haber encargado un poema de esta temática con el que agradar a la soberana? Aunque no hay forma de saber si Constanza o su hijastra Philippa quisieron ganarse el favor de la reina para su causa española, o simplemente compartir con ella estos gustos por los personajes clásicos, la posibilidad está ahí, dada su cercanía a Chaucer.

Pero si la lisonja y la petición de favor político es uno de los elementos que explicarían la redacción del poema, no hay duda de que la temática de la mujer con relación al amor y a la literatura también fue un tema importante para quien patrocinó la obra. Son de destacar otros versos más reveladores del parecer de las damas con respecto a la misoginia del momento, como veremos. En el prólogo el relator, tras pasear por el jardín, cae rendido en su cama y en un sueño singular vislumbra al dios Amor con su reina, ataviada de verde, seguido de diecinueve bellas damas con atuendo real y de otra enorme comitiva femenina tras ellas, todas descritas como fieles servidoras del dios, al que entonan una loa. En el poema, Amor se identifica con las damas; así pues, una afrenta a él conlleva la enemistad femenina, que el poeta parece haberse granjeado: Amor le recrimina duramente el trato que le ha dado tanto a él como a las mujeres en sus composiciones, y en particular su traducción del Román de la rose al inglés. Dice así (2005: 137):

[...] con tu traducción manipulas a la gente para que no me sirva y sostienes que es una locura servir al Amor. No puedes negarlo porque has traducido El libro de la rosa a un texto sencillo, sin necesidad de glosarlo, lo cual es una herejía contra mis leyes; has hecho que la gente culta me abandone.

Posiblemente la acusación del dios al poeta refleje lo que fue el sentir de la corte ante la traducción de parte del poema al inglés; el dios se queja del abandono de la gente culta, que no se siente ya identificada con él. Dado que Chaucer no tradujo los fragmentos más misóginos de la obra, puede que esta queja de Amor no sea sino el eco de un creciente malestar entre las damas de la corte -mujeres cultivadas que conocerían y podrían leer el original francés - contra el trato que dicho libro daba a las mujeres; será este malestar el que evidenciará diez años después Cristina de Pizan en el llamado "Debate de la rosa". Precisamente cuando Cristina acuse a Jean de Meung - el segundo autor de Le roman de la rose- de difamar a las mujeres, a ella se le reprochará su lectura literal - y por tanto femenina-, que la incapacita para superar el sentido básico y carnal de la obra. Y es de esto precisamente de lo que Amor acusa a Chaucer, de haber sido demasiado literal en su traducción, sin haberse percatado de que había ecos ocultos en la obra francesa que no había captado. Así pues, el propio Chaucer es acusado de literalidad y femineidad, de no ser capaz de transmitir la profundidad y auténtica dimensión del amor.

Más aún, en los versos siguientes, Amor se refiere a cómo en su anterior poema, "Troilo y Criseida", Chaucer había elegido como heroína a la viuda Criseida. 
Por imperativos políticos ésta había abandonado al que había sido su amante, el príncipe Troilo, que, totalmente decepcionado, muere en el campo de batalla troyano a manos de los griegos. Dicen los versos (p. 137): "De Criseida, que es tan fiel como siempre lo fue cualquier acero, has dicho lo que te ha dado la gana, lo que hace que los hombres confíen menos en las mujeres". Amor es quien refiere a Criseida como una fiel amante para Troilo, comparando su constancia a la del acero; sin embargo dice que el poeta la ha transformado en infiel, y que por esta torpeza los lectores han venido a creer que todas las mujeres lo son. Se le acusa de propiciar la misoginia entre los lectores, y sin embargo, se añade que la protagonista femenina había sido fiel en el amor a pesar de su traición. Así, con esta autoacusación, Chaucer estaría evidenciando que había dos posturas diversas sobre el amor: la primera, que partía de la sublimación del amor cortés como manifestación de una predisposición natural hacia la conducta noble de quienes lo sentían y practicaban, y otra segunda, mucho más atenta a integrar este sentimiento en una amalgama de respuestas psicológicas condicionadas por los acontecimientos externos. En el caso de Griselda, el absolutismo del amor cortés ha de flexibilizarse ante los traumas de la guerra, que imponen una conducta nueva e inaceptable en el modelo cortés. Chaucer muestra aquí los primeros signos de disconformidad con el primer modelo, que acentuará más tarde, cuando en algunos de los relatos de Los cuentos de Carterbury parodie a los edulcorados amantes corteses y su código de conducta, tan artificial como ineficaz. Podemos, pues, hablar de cierto clima de debate que se habría extendido en la corte a partir de la lectura de relatos que enfrentaban el modelo del amor cortés a otros comportamientos amorosos que superaban dicho marco idealizador, como es el relato de Troilo y Criseida.

Llegado este punto, el dios Amor es interrumpido por su dama principal, Alceste, quien trata de defender al poeta, arguyendo diversas excusas que expliquen la composición de Troilo y Criseida y la traducción de Le roman de la rose. Entre ellas, menciona la posibilidad de que alguien le haya encargado la redacción de estos dos poemas y de que él no se haya podido negar al encargo de un/a superior (p.138):

[...] También puede ocurrir que este hombre esté loco y podría haberlo pensado sin malicia, pues suele escribir sin poner cuidado en los asuntos que trata. $\mathrm{O}$ quizás alguna persona le encargó componer esos dos trabajos y no se atrevió a rechazarlos, o él se ha arrepentido completamente de esto. [...] Ahora, puesto que eres un dios y también un rey, yo, tu Alcestis, una vez reina de Tracia, te pido, por tu generosidad, que no dañes a este hombre nunca en toda su vida y él te jurará inmediatamente que no ofenderá de esta forma, sino que escribirá como tú le indiques sobre mujeres fieles en el amor durante toda su vida, bien estuvieran solteras o casadas, y más sobre ti, tanto como habló mal en la Rosa o también en Criseida.

Alceste impone la escritura de un poema dedicado a glosar la figura de mujeres excepcionales que han sido traicionadas por sus amantes -que compense la traición de Criseida para con Troilo- y se despide del poeta de esta forma (p. 139):

Y aunque tú, desgraciadamente, no eres amante, hablas sobre el amor. Esta penitencia te impongo. Y al dios del Amor le ruego que les encargue a sus sirvientes que de alguna manera te ayuden y recompensen bien tu trabajo. Sigue ahora tu camino, tu penitencia es poca. Cuando tengas el libro escrito, entrégaselo a la reina de mi parte en la residencia de Eltham o en la de Sheene.

Así, refiriéndose al pago que se ha de dar por este poema cuando esté acabado, se anuncia su presentación ante la reina, que refiere de forma ficticia el encargo al poeta. No es de extrañar que en la mayor parte de estas leyendas las 
figuras femeninas sean mujeres poderosas, capaces, por ejemplo, de ofrecer hospitalidad a los héroes fugitivos, organizar fugas de las prisiones o emprender batallas. Sin embargo, el rasgo que las une no es el poder sino la disposición a creer en los hombres y a sacrificarse por ellos. Así, de nuevo, es la lectura literal de la voluntad masculina lo que caracteriza a las protagonistas; es la literalidad la que convierte a las heroínas en víctimas y mártires del amor, por lo que podemos afirmar que el poeta de nuevo enemista a las mujeres con el amor, al destacar cómo aquél las ciega y las aleja de un entendimiento certero de los hombres, los únicos que hablan con doble intención. Así, subrepticiamente denuncia la religión del amor como un instrumento ideológico culturalmente erigido para disipar la posibilidad de autonomía femenina, tal y como delatará años más tarde Cristina de Pizan en su "Epístola del dios Amor". Pero Chaucer, consciente en todo momento de su condición de servidor de los gustos e intereses cortesanos, ha de recurrir a la autorrepresentación, la ambigüedad y la ironía para evadir las presiones a que estaba expuesto, tanto por parte de los caballeros como de las damas: al representarse a sí mismo como incapaz de profundizar en el sentido oculto del amor, desnuda con su supuesta inocencia el lado más destructivo de este sentimiento, y deja abierto a las damas de la corte el tema de debate.

El poeta tiene hoy en día fama de ser un auténtico maestro en el arte de la polifonía textual, imagen en la que ha influido tanto que en "La leyenda de las buenas mujeres" como en otras obras señeras aparezca como un simple, incapaz de superar el grado de lo literal. Su constante recurso al tema del debate existente entre hombres y mujeres nos habla de un momento en que las damas inglesas pudieron organizarse en torno a la lectura y el comentario literario para exigir modelos femeninos como los de estas buenas mujeres, que si bien aparecen sujetas a la pasión amorosa, representan y mantienen eficazmente el poder por sí mismas. La capacidad de gestión cultural de las damas de la corte inglesa queda constatada por su implicación en la promoción y protección a poetas como éste, cuyo eco de la temática de las mujeres se ha mantenido hasta la actualidad. Esta labor de mecenazgo de mujeres como Blanca de Lancaster, la reina Ana de Bohemia o Constanza de Castilla a menudo ha quedado olvidada, si bien su velada influencia en la poesía de Chaucer sí que ha permanecido. Esta persistencia dice mucho sobre los reductos de poder que las damas iban acotando y sobre el tipo de literatura que estos círculos consumirían a partir de una selección femenina.

\section{Conclusión}

Tradicionalmente se ha pensado que la vinculación de las mujeres del Medievo a los libros venía simplemente a sellar un proceso por el que la cultura patriarcal se inscribiría lentamente en la psique femenina, a medida que toda una serie de modelos de mujeres antiguas y contemporáneas forjaran los prototipos de conducta abnegada y dócil que hemos imaginado para estos siglos. Si bien este extremo es innegable, también lo es que las mujeres fueron auténticas privilegiadas en su relación con la literatura. Bien desde el ámbito doméstico al que habían sido relegadas, bien desde los claustros en que se habían internado a voluntad, muchas tuvieron la posibilidad de leer y compartir con los clérigos cercanos una cultura que durante los primeros tiempos fue rechazada por los hombres como actividad no viril. Frente a las limitaciones que se percibían en la vida diaria, la lectura les proporcionó un dominio distinto, más amplio y variado que el de la existencia cotidiana. Las mujeres pronto empezaron a reproducir su propio universo, poblado de fantasías como las recreadas por María de Francia, o de intensas relaciones espirituales, como las desarrolladas en las visiones de las místicas. A partir del siglo XII, la llegada de leyendas ovidianas y del mundo clásico en su conjunto, proporcionó a muchas de las damas de estos momentos un modelo alternativo al de la figura de la santa. Fue, en definitiva, alrededor de la lectura como estas damas empezarían a desprenderse de su condición 
de mero tejido textual sobre el que hablan o escriben los doctos y misóginos, y a recuperar una capacidad lingüística que les permitiría asumir una conducta claramente política en su apreciación de los sexos. Conscientes de la importancia de la palabra, las damas de la corte inglesa reclaman respeto para las mujeres; para todas, también para las literarias, pues en ellas se mirarían diariamente. Su disposición hacia ciertos temas y tratamientos de las figuras femeninas nos revela que fueron activas en su defensa de la virtud femenina: el hecho de que muchas de las heroínas aparezcan como eficientes regentes con un alto grado de autonomía y el que todas las historias redunden en la peligrosa simbiosis que existe entre lo privado y lo público evidencian algunos de los intereses de estos grupos de lectoras y su intento de superar la inercia del poder desde una posición común.

\section{Notas}

${ }^{1}$ No hay más que hojear, al menos para el mundo angloparlante, los ya cuarenta números del Medieval Feminist Newsletter, en los que se advierte una mayor presencia de estos temas, y entre los que sobresale el estudio individual de mujeres poderosas. En cuanto a esta aportación particular, procede de la comunicación que presenté en el XIII Coloquio Internacional de la Asociación Española Internacional de Historia de las Mujeres, celebrado en Barcelona en octubre de 2006. Agradezco a Inés Castro Apreza su atenta lectura y sugerencias, fruto de las cuales es este artículo.

${ }^{2}$ En efecto, para autores como Filón, Tertuliano, Clemente de Alejandría, Juan Crisóstomo, Cipriano, Ambrosio o Jerónimo existe una predisposición femenina hacia lo ornamental, una fascinación por lo decorativo que proviene de su propia condición de criaturas secundarias, creadas a partir del primigenio cuerpo masculino y del lenguaje con que el hombre designa y condensa su universo (Colish, 1981: 3-14).

${ }^{3}$ Sabemos que en esta ocasión, la reina Felipa se encargó de ofrecerles hospitalidad, hasta el punto de que cada uno de ellos contaba con su propia corte (Butterfield, 1997: 92). Juan II de Francia había sido patrón de Machaut, uno de los poetas más respetados por Chaucer, y asimismo había recibido a Petrarca en su corte. Sus gustos literarios se traducían, pues, en la cantidad de libros y artistas que hizo traer tanto a su corte francesa como a la inglesa en que fue recibido. Mientras, su hijo Jean, que estuvo desde 1360 hasta el 67 durante largos periodos en la corte inglesa, también dedicó varios de sus poemas al amor y posiblemente conoció al joven Chaucer.

${ }^{4}$ El caso de Jean Froissart es ejemplar, pues lo encontramos entre el séquito que acompaña a la reina Felipa de Hinault desde Bélgica en 1360, transformándose durante siete años en testigo directo de los sucesos que acontecieron en la corte inglesa en los momentos en que la llamada Guerra de los Cien Años alteró la suerte de las diversas monarquías. Pero además de Froissart, la corte inglesa había contado con figuras como Jean de la Mote (músico y poeta que alternaría su trabajo en la cancillería con encargos como el que recibió en 1339 de la reina para que compusiera una elegía para su padre, Guillermo, conde de Hinault), Jehan le Bel (que había luchado al servicio de Eduardo en Escocia en 1327, precediendo a Froissart en la corte), el influyente Philippe de Vitry (amigo de Juan II, así como de Petrarca y de Pierre Bersuire), Otto de Granson (quien entró al servicio real en 1374 para, a continuación, pasar al séquito de Lancaster y posteriormente de Ricardo II hasta 1387, fecha en la que retornaría a su hogar en Savoya, regresando entre 1392 y 96. Oton sería un gran amigo de Chaucer, de forma que se puede rastrear una mutua influencia en su poesía).

${ }^{5}$ La elección de la lengua materna de Chaucer lo vincula no sólo a la labor de poetas tan señalados como Dante, sino también a un movimiento que comienza entre la población femenina de diversos países en la Baja Edad Media, el del desarrollo de la literatura vernácula por mano, la mayor parte de las veces, de mujeres religiosas.

${ }^{6}$ Sigue a Lionel a una de las campañas francesas, donde se le hace prisionero y se le rescata en 1360 por dieciséis libras, apareciendo no ya como paje, sino como «valettus» 
real. James Root Hulbert (1912) destaca que la suerte del poeta y sus progresos entre la nobleza no eran exclusivos, y proporciona un informe sobre los compañeros de armas y sirvientes de procedencia parecida que estaban en su misma situación. Recordemos que este patriciado urbano de fines del XV constituye un auténtico semillero para el funcionariado real durante el siglo XV.

${ }^{7}$ Este descubrimiento fue hecho por Suzanne HonoréDuvergé (1955: 9-13), quien planteó que Chaucer pudo visitar la península como soldado de fortuna en la Gran Compañía de du Guesclin, formada para auxiliar a Enrique. No obstante, últimamente ha pesado más la propuesta contraria (Garbáty, 1967: 81-87; Galván, 1989: 98-111), que lo presenta como agente de la corona en favor precisamente de Pedro I. Si bien ha habido varias revisiones de la relación entre España y su literatura y la obra chauceriana (León Sendra y Serrano Reyes, 1992: 106-41; Shaw, 1993: 41-54; Lázaro Lafuente, 1995: 18-28), el caso más sugerente sobre esta relación lo ofrece Serrano Reyes (1998: 193-203) que cree que entre los salvoconductos que recibiría el escudero, habría uno para su propia esposa, Philippa, con la que se habría casado pocos meses antes.

${ }^{8}$ Esto tiene sentido si se contrasta con la información que ofrece el canciller de Ayala. Dado que Calveley abandonó a Enrique y participó en su contra en Nájera, el monarca aragonés Pedro el Ceremonioso, con quien ya había trabado amistad desde su apoyo a Enrique, le ofrece en casamiento a la princesa Constanza, para de esta forma afianzar lazos con los ingleses. Suárez Fernández (1970, p. 444) dice al respecto: "Las tropas inglesas y francesas indistintamente, comenzaron a pasar por Cataluña en enero de 1366. Pedro IV hizo objeto de especiales atenciones a los capitanes británicos para conservar un puente tendido hacia la amistad inglesa".

${ }^{9}$ Allí, su antiguo señor, Lionel, tras enviudar, preparaba nupcias con Violante Visconti. Aunque la boda se celebra, Lionel fallece durante el viaje y el poeta ha de regresar a la corte sin él Años más tarde, al viajar a Génova en 1372 para establecer un pacto de protección de los intereses genoveses en el comercio con Inglaterra, Chaucer permanece en Italia al menos tres meses, conociendo la Florencia del Trecento, y haciendo del venerado Dante su principal modelo. Su influencia se evidencia en la obra de estos años, mientras que la de Petrarca y Boccaccio parece proceder de la huella que dejaría el segundo viaje a Italia en la memoria y en la biblioteca del poeta.

${ }^{10}$ Hulbert (op. cit.) ofrece argumentos convincentes en contra del "idilio" Chaucer/Gante que cree edificado por una crítica ansiosa de relacionarlos. De cualquier manera, para Juan de Gante escribiría "The book of the Duchess", evidenciando su asimilación de la literatura alegórica contemporánea y de la semilla de aquélla, Le roman de la rose. Con esta elegía para la dama muerta, el poeta profetiza una época de decadencia para la familia real, que se traducirá en la enfermedad y muerte del Príncipe Negro en 1376 y de su padre, Eduardo III, al siguiente año, al tiempo que los progresos en Francia y la intervención en España quedan también en punto muerto.

${ }^{11}$ Se dirige a la corte de Bernabo Visconti, donde permanece seis semanas para reforzar una política común en lo tocante probablemente al cisma eclesiástico y a la guerra con Francia (Braddy, 1933: 507-51l; Manly, 1934, pp. 209-216; Kuhl, 1947, pp. 42-44; Pratt, 1949, pp. 188-193).

${ }^{12}$ Según Ybarra (op. cit.: 167-8): "La importancia de la conjunción futura de las dos más poderosas flotas marítimas de Europa despertó en todos los ingleses grandes esperanzas de derrotar definitivamente a Francia. Los tres hijos de Lancaster, Felipa, Isabel y Enrique, también acogieron con alegría y satisfacción a Constanza, pues su llegada a Londres marcó el final del luto y del duelo impuesto por la muerte de su madre; las fiestas y la alegría retornaron al espléndido palacio de Savoy Court, que era la residencia en Londres de Lancaster, así como a los magníficos castillos de Hereford y de Leicester en el campo".

${ }^{13}$ Dado que Serrano defiende que Philippa Chaucer sería uno de los tres acompañantes del poeta en su misterio- 
so viaje a Navarra, sería factible, pues, que hubiera de nuevo visitado el país, ahora con su señora castellana, y que incluso hubiera llevado con ella a su hijo mayor, Thomas. Aunque en febrero de 1386 Philippa es admitida a la fraternidad de la catedral de Lincoln, lo que supone un fuerte vínculo con su hermana y los hijos de ésta, Serrano no ve este dato como óbice para su viaje a Portugal con los Lancaster.

${ }^{14}$ Fernando de Ybarra (op.cit:: 313) dice al respecto: "Constanza vivía muy dedicada a las obras benéficas y las prácticas religiosas; su atención a la abadía de St. Albans había dado motivo para que la nombrasen protectora y patrona de la comunidad cisterciense de la abadía, con la que gustaba compartir horas de oración y de meditaciones teológicas. Frecuentaba la compañía de obispos, existiendo referencias de sus visitas al obispo Braybrooke, de Londres, en su residencia campestre de Hertfordshire, donde incluso participó en jornadas de caza."

${ }^{15}$ Mientras que H. Braddy (1935: 69-80) sostiene que el principal informante habría sido el amigo de Chaucer Sir Guichard d'Angle, H. Savage (1949: 357-75), mantiene a Fernando de Castro como fiel informante del suceso.

${ }^{16}$ Fernando de Ybarra (op. cit.) aclara que, efectivamente, cuando Pedro I supo que las compañías francesas estaban ya en Languedoc, solicitó la ayuda inglesa, pero Eduardo III desvió dicha solicitud al Príncipe Negro, quien no parece haberse tomado en serio la amenaza, pues no impidió que algunos mercenarios ingleses y gascones se alistasen en estas compañías; entre ellos, Sir Hugh Calveley.

${ }^{17}$ Según Savage (op. cit:: 364): "the bastard version therefore, must have been written at some time earlier than 1386, when there was no need to conciliate the usurping house of Trastamara". Sobre estos momentos, Ayala (op.cit.: 623) relata episodios de tensión sobre el tema de la bastardía enriqueña, y así sabemos que el obispo Juan de Aquis defendía el derecho de la duquesa Constanza con palabras como "Otrosí dice que el dicho rey don Alfonso casó una su fija bastarda, que decían doña Beatriz...", tratando así de demostrar que Enrique Trastámara era el hermano bastardo de Pedro. Pero tras esta discusión Thomas de Percy fue enviado al rey de Castilla, y Ayala no cuenta más sobre los resultados, aunque sabemos que en 1387, tras retirarse Lancaster a Portugal, Juan I envía embajadores a Troncoso, y Juan de Gante, dejando Portugal hacia Bayona, decide llegar a un acuerdo con aquél por el que aceptará la compensación económica y el enlace entre su hija y el hijo de aquél como modo de cerrar su aventura castellana.

${ }^{18}$ En este sentido, Chaucer seguía a Deschamps, quien ya había introducido este binomio como tema de su poesía. Curiosamente, el propio Deschamps se había referido a Chaucer como gran traductor a partir de su versión de Le roman de la rose. El poema, pues, puede leerse como respuesta a toda una serie de autoridades, desde Ovidio hasta Boccaccio o Deschamps, que constituyen fuente innegable de su obra.

\section{Bibliografía}

Anderson, M., 1947, "Blanche Duchess of Lancaster", en Modern Philology, vol. 45, pp. 152-59.

Baugh, Albert Croll, 1968, "The background of Chaucer's mission to Spain", en Chaucer und Seine Zeit,Symposion für Walter F. Schirner, N. Niemeyer, Tübinggen, pp. 55-69.

Bloch, Howard, 1991, Medieval Misogyny and the Invention of Western Romantic Love, The University Press of Chicago, Chicago y Londres.

Braddy, Haldeen, 1933, "New documentary evidence concerning Chaucer's mission to Lombardy”, en Modern Language Notes, vol. 48, pp. 507-11.

-, 1935, "The two Petros in the 'Monkes Tale", en PMLA, vol. 50, pp. 69-80.

— ,1949, "Chaucer's Philippa, daughter of Panetto", en Modern Language Notes, vol. 64, pp. 342-43.

Butterfield, Ardis,1997, "French culture and the Ricardian Court", en Alistair Minnis, Charlote Morse y Thorlac Turville-Petre (eds.), Essays on Ricardian Literature in Honour of J. A. Burrow, Clarendon, Oxford, pp. 82-12. 
Calin, William, 1984, The French Tradition and the Literature of Medieval England, University of Toronto Press, Toronto. Chaucer, Geoffrey, 1987, Los cuentos de Canterbury, Pedro Guardia Massó (ed. y trad.), Cátedra, Madrid.

— , 2005, El Parlamento de las Aves y otras visiones del sueño, Jesús Serrano (ed. y trad.), Siruela, Madrid.

Colish, Marcia, 1981, "Cosmetic theology: the transformation of a Stoic theme", en Assais, vol. 1, pp. 3-14.

Crow, Martin y Clair Olson (eds.), 1966, Chaucer's Life Records, Clarendon, Oxford.

Cullum, Patricia y Jeremy Goldberg, 2000, "How Margaret Blackburn taught her daughters: reading devotional instruction in a book of hours", en Jocelyn Wogan-Browne et al. (eds.), Medieval Women: Texts and Contexts in Late Medieval Britain, Essays for Felicity Riddy, Turnhout, Brepols, pp. 217-236.

Galván, Fernando, 1989, "Medieval English Literature: A Spanish Approach", en Patricia Shaw, Antonio Bravo, Santiago Fernández y Francisco García (eds.), Actas del I Congreso Internacional de la Sociedad Española de Lengua y Literatura Inglesa y Medieval, Universidad de Oviedo, Oviedo, pp. 98-111.

Galway, Margaret, 1960, "Philippa Pan; Philippa Chaucer", en Modern Language Review, vol. 60, pp. 481-87.

Garbáty, Thomas Jay, 1967, "Chaucer in Spain, 1366: soldier of fortune or agent of the Crown?", en English Language Notes, vol. 5, pp. 81-87.

Honoré-Duvergé, Suzanne, 1955, "Chaucer en Espagne? (1366)", en Recueil de trabaux offert à M. Clovis Brunel, Société l'École des Chartres II, París, pp. 9-13.

Jambeck, Karen, 1996, "Patterns of literary patronage: England, 1200-ca. 1475”, en June Hall McCash (ed.), The Cultural Patronage of Medieval Women, The University of Georgia Press, Athens y Londres, pp. 228-265.

Kuhl, E. P., 1947, "Why was Chaucer sent to Milan in 1378?", en Modern Language Notes, vol. 62, pp. 42-44.

Lázaro Lafuente, Luis Alberto, 1995, "Some speculations about Chaucer's Spanish Literary Sources", en Selim, vol. 5, pp. 18-28.
León Sendra Antonio y Jesús Serrano Reyes, 1992, «Spanish references in The Canterbury Tales», en Selim, vol. 2, pp.106-41.

López de Ayala, Pedro, 1991, Crónicas, José Luis Martín (ed.), Planeta, Barcelona.

Manly, John M., 1934, "Chaucer's mission to Lombardy", en Modern Language Notes, vol. 49, pp. 209-16.

Meale, Carol, 1993, “....Alle the bookes that I have of Latyn, Englisch and Frensch': Laywomen and their books in late medieval England", en Carol Meale (ed.), Women and Literature in Britain, 1150-1500, Cambridge University Press, Cambridge, pp. 128-158.

Penketh, Sandra, 1997, "Women and books of hours", en Lesley Smith y Jane H. M. Taylor (eds.), Women and the Book. Assessing the Visual Evidence, The British Library and The University Press of Toronto, Toronto y Búfalo, pp. 266-280.

Potkay, M. Brzezinski y Regula Meyer Evitt, 1997, Minding the Body: Women and Literature in the Middle Ages, 8001500, Twayne, Londres.

Pratt, Robert, 1949, "Geoffrey Chaucer, esq., and Sir John Hawkwood", en Journal of English Literary History, vol. 16, pp. 188-93.

Rigg, A. C., 1997, "Anglo-Latin in the Ricardian age", en Alistair Minnis, Charlotte Morse y Thorlac TurvillePetre (eds.), Essays on Ricardian Literature in Honour of J. A. Burrow, Clarendon, Oxford, pp. 121-41.

Root Hulbert, James, 1912, Chaucer's Official Life, The Collegiate P., George Banta Publishing, Menasha, Wisconsin.

Savage, Henry, 1949, “Chaucer and the 'pitous deeth' of 'Petro, glorie of Spayne”, en Speculum, vol. 24, pp. 357-75.

Serrano Reyes, Jesús, 1995, "John of Gaunt's intervention in Spain: possible repercussions for Chaucer's life and poetry", en Selim, vol. 6, pp. 117-145.

—, 1998, "The Chaucers in Spain: from the wedding to the funeral", en Selim, vol. 8, pp.193-204.

Shaw, Patricia, 1993, "The presence of Spain in Middle English literature", en Archiv für das Studium der Neueren Sprachen und Literaturen, vol. 229, pp. 41-54. 
Sheingorn, Pamela, 2003, "The 'wise mother': The image of St Anne teaching the Virgin Mary", en Mary C. Erler y Maryanne Kowaleski (eds.), Gendering the Master Narrative: Women and Power in the Middle Ages, Cornell University Press, Ithaca y Londres, pp. 105-134.

Suárez Fernández, Luis, 1970, Historia de España, vol. I, Gredos, Madrid.
Webster, Norman W., 1990, Blanche of Lancaster, Halstead, Driffield.

Wimsatt, James, 1993, Chaucer and His French Contemporaries: Natural Music in the Fourteenth Century, University of Toronto Press, Toronto y Londres.

Ybarra, Fernando de, 1999, Matrimonios reales hispanobritánicos en el medievo, tomo II: "La reina de diamantes", Universidad Pontificia, Salamanca. 